\title{
The Variation in the Depth of Overburden at Different Ves Points within Samaru Using D.C. Resistivity Technique
}

\author{
Afuwai Gwazah Cyril \\ Department of Physics, \\ Federal University, Dutsin-Ma, Nigeria
}

\author{
Doi:10.5901/ajis.2013.v2n12p95
}

\begin{abstract}
The interpretation of 32 Schlumberger vertical electrical sounding (VES) data was carried out at Samaru College of Agriculture, A.B.U, Zaria, Sabongari Local government area of Kaduna State, Nigeria. This is an attempt to investigate the groundwater potential and the geologic characteristics of the overburden of the area. Terrameter signal averaging system (SAS) model 300 was the instrument used. No booster was used as the expected depth is within the range of penetration of the instrument. In this instrument consecutive readings are taken automatically and the results averaged continuously and displayed. The schlumberger electrode configuration was used in the data acquisition. The field procedure consists of expanding $A B$ (distance between current electrodes) while MN (distance between potential electrodes) is fixed. This process yields a rapidly decreasing potential difference across $M N$, which eventually exceeds the measuring capacity of the instrument; therefore a larger value for $M N$ was taken to continue with the survey. The VES curves were interpreted using IPI2Win resistivity computer software. The survey area is dominated by mainly four layers, namely: Overburden, Weathered basement, fractured basement and Fresh basement. The overburden consists of laterites, clay and fadama loam. The results of the interpreted VES data showed that The Overburden thickness varies from 1.3 to $5.2 \mathrm{~m}$, with an average of $3.1 \mathrm{~m}$. The lowest overburden depth is at VES2O where the depth to basement is as low as $6 \mathrm{~m}$. A map was produced by contouring all the overburden depths at each VES point at an interval of $0.5 \mathrm{~m}$. The map shows the variation of the topsoil depth from one place to another within the survey Area which is an indication of the inhomogenuity of the subsurface structures. The thickness of the aquifer varied from 1-35m with an average of $18 m$.
\end{abstract}

Keywords: Resistivity1, Overburden2, Subsurface

\section{Introduction}

Water is essential to people and the largest available source of fresh water lies underground. Increased demands for water have stimulated development of underground water resources. As a result, techniques for investing the occurrence and movement of groundwater have been improved, better equipment for extracting groundwater has been developed, and concepts of resource management have been established. Groundwater is commonly understood to mean water occupying all the voids within a geologic stratum. This saturated zone is distinguished from an unsaturated zone, where voids are filled with water and air. Water contained in saturated zones is important for engineering works, geologic studies, and water supply developments (Afuwai et al, 2011).

The Samaru College of Agriculture, Zaria is located at a longitude of $11^{\circ} 09^{\prime} 48.60$ "N to $11^{\circ} 10^{\prime} 02.93^{\prime} \mathrm{N}$ and at a Longitude of $7^{\circ} 38^{\prime} 06.45^{\prime} \mathrm{E}$ to $7^{\circ} 3920.54^{\prime} \mathrm{E}$ in the sabongari local government area (L.G.A) of Kaduna state, Nigeria (Figure 1). The college is part of the Ahmadu Bello University, Zaria, and it is bounded in the east by the estate management department of the university and 
Institute of Agricultural research (I.A.R), and in the west by Area G Staff quarters. The study area has dry season (November to April) and wet season (May to October) with rain falling mainly during the wet season with an average annual rainfall of about $109 \mathrm{~cm}$ (Hore, 1970). The college is accessible mainly through the Zaria-Shika main road. (Figure2).

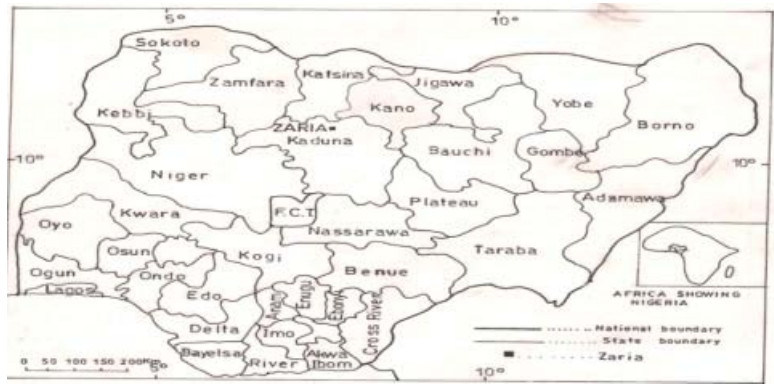

Figure 1. Map of Nigeria showing Zaria-Kaduna.

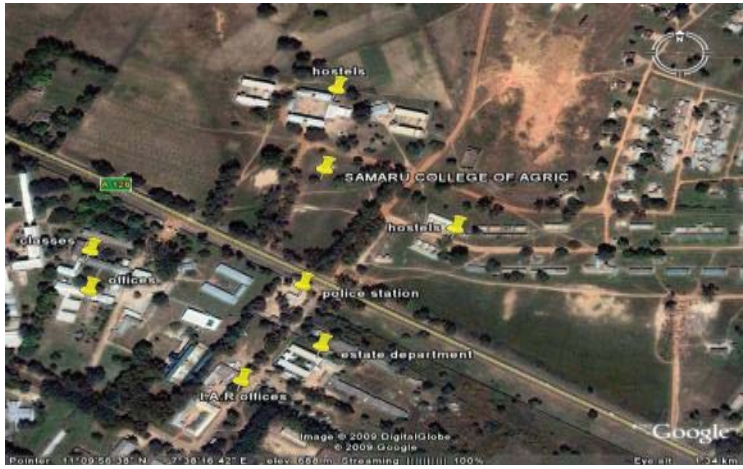

Figure 2. Satellite image of the study Area. Source: Google Earth (2009).

\section{Objectives}

This study aims at using ABEM Terrameter SAS 300 to carry out a geophysical survey to achieve the following Objectives:

- Determination of the depth of Overburden at different VES Points.

- To contour the Overburden depths at different VES Points within the survey Area.

- To establish Areas within the Overburden that is suitable for waste disposal system.

\section{Methodology}

In the DC resistivity surveying, an electric current is passed into the ground through two outer electrodes ( $A$ and $B$ ), and the resultant potential difference is measured across two inner electrodes $(\mathrm{M}$ and $\mathrm{N}$ ) that are arranged in a straight line, symmetrically about a centre point Figure3. The ratio of the potential difference to the current is displayed by the Terrameter as resistance. A geometric factor in metres is calculated as a function of the electrode spacing. The electrode spacing is progressively increased, keeping the centre point of the electrode array fixed. 


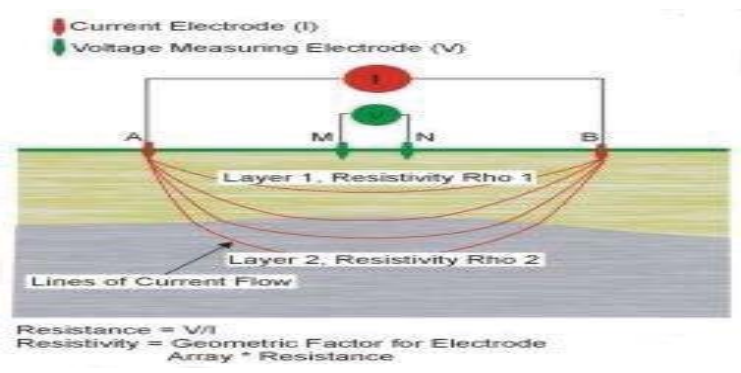

Figure 3. Shows a schematic diagram of the schlumberger array used in the survey

$A$ and $B$ are current electrodes through which current is supplied into the ground, $\mathrm{M}$ and $\mathrm{N}$ are two potential electrodes to measure the potential differences between the two electrodes and $\mathrm{P}$ is the VES station to be sounded. The potential difference between the two potential electrode is measured. The apparent resistivity is given by $\rho_{a}=\mathrm{k}(\Delta \mathrm{V} / \mathrm{I})$ with $\mathrm{K}$ a geometric factor which only depends on electrode spacing. The apparent resistivity is the ratio of the potential obtained in-situ with a specific array and a specific injected current by the potential which will be obtained with the same array and current for an homogeneous and isotropic medium of $1 \Omega m$ resistivity. The apparent resistivity measurements give information about resistivity for a medium whose volume is proportional to the electrode spacing (Shemang, 1990). Resistivity is affected more by water content and quality than the actual rock material in porous formations. While aquifers that are composed of unconsolidated materials their resistivity decreases with the degree of saturation and salinity of the groundwater (Aboh, 2001).

\section{Results and Discussion}

The data analysis for the VES was performed using IPI2Win's new method for the automatic interpretation of schlumberger sounding curves. This method was used to obtain the model for the apparent resistivity of each sounding. The survey area is dominated by mainly four layers, namely: Overburden, Weathered basement, fractured basement and Fresh basement. The overburden consists of laterites, clay and fadama loam. The results of the interpreted VES data showed that The Overburden depths vary from 1.2 to $7.2 \mathrm{~m}$, with an average of $4.1 \mathrm{~m}$. The lowest overburden is at VES20 where the depth to basement is as low as $10 \mathrm{~m}$. A map was produced by contouring all the depths of the overburden layers at each VES point at an interval of $0.5 \mathrm{~m}$. The map shows the variation of the topsoil thickness from one place to another within the survey Area which is an indication of the inhomogenuity of the subsurface structures. The interpretation of all the VES points ( 01 to 32 ) is shown in table 2 below.Based on the IPI2Win's method, the field curves were found to be averagely four (4) layers. Tablel shows the interpretation of VES POINT 01, and figure4 shows a typical digitized curve for VES POINT 01. The interpretation of all the VES points (01 to 32) is shown in Table2.

Table1: Interpretation of Ves Point 11.

Depth to basement at Ves Point 11 is $11.24 \mathrm{~m}$.

\begin{tabular}{|c|c|c|c|}
\hline Layer no. & Resistivity (ohm-m) $\rho$ & Thickness $(\mathrm{m}) \mathrm{h}$ & Depth $(\mathrm{m}) \mathrm{d}$ \\
\hline 1 & 367.8 & 1.561 & 1.561 \\
\hline 2 & 411.9 & 0.3184 & 1.879 \\
\hline 3 & 143.9 & 9.365 & 11.24 \\
\hline 4 & 672.9 & - & - \\
\hline
\end{tabular}


In figure4; Apparent resistivity $\left(\rho_{a}\right)$ in ohm-metres is plotted against the electrode spacing $(A B / 2)$ in metres by the computer software IPI2Win on a log-log scale. The blue color gives the number of layers, the red color indicate the synthetic curve while the black color shows the curve for the field data.

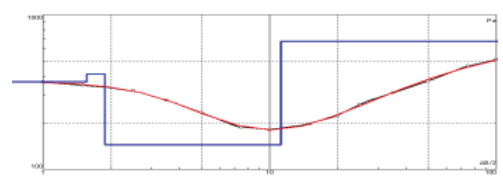

Figure 4. Shows a typical digitized curve for VES POINT 11.

Table 2. Interpretation of VES Points 01 to 32.

\begin{tabular}{|c|c|c|c|c|c|c|c|c|c|c|c|}
\hline VES & AZI MUTH & $\rho_{1}(\Omega m)$ & $h_{1}(m)$ & $\rho_{2}(\Omega m)$ & $h_{2}(m)$ & $\rho_{3}(\Omega m)$ & $h_{3}(m)$ & $\rho_{4}(\Omega m)$ & $h_{4}(m)$ & $\rho_{5}(\Omega \mathrm{m})$ & $h_{5}(m)$ \\
\hline 01 & NW-SE & 367.8 & 1.561 & 411.9 & 0.3184 & 143.9 & 9.365 & 672.9 & - & - & - \\
\hline 02 & NE-SW & 258 & 1.48 & 137 & 2.65 & 62.1 & 8.05 & 558 & - & - & - \\
\hline 03 & $\mathrm{~N}-\mathrm{S}$ & 283 & 0.566 & 186 & 2.13 & 49.1 & 9.85 & 611 & - & - & - \\
\hline 04 & $E-W$ & 290 & 1.27 & 578 & 2.88 & 1413 & 2.16 & 3821 & - & - & - \\
\hline 05 & $\mathrm{~N}-\mathrm{S}$ & 130.6 & 2.633 & 1713 & 2.856 & 516.5 & 5.97 & 738.9 & - & - & - \\
\hline 06 & N-S & 97.9 & 0.6 & 139 & 1.62 & 1068 & 4.86 & 1963 & - & - & - \\
\hline 07 & E-W & 333 & 1.26 & 181 & 4.23 & 69.6 & 7.77 & 2009 & - & - & - \\
\hline 08 & E-W & 55 & 0.7 & 73.2 & 3.7 & 1273 & 2.99 & 114 & - & - & - \\
\hline 09 & E-W & 58.4 & 1.13 & 76.3 & 3.62 & 679 & 4.5 & 141 & - & - & - \\
\hline 10 & $\mathrm{~N}-\mathrm{S}$ & 116 & 0.915 & 292 & 0.457 & 101 & 1.77 & 568 & 13.3 & 316 & - \\
\hline 11 & E-W & 148 & 0.409 & 754 & 0.368 & 69.3 & 18.3 & 10512 & - & - & - \\
\hline 12 & E-W & 136 & 0.6 & 313 & 0.654 & 69.2 & 4.24 & 155 & 45 & 419 & \\
\hline 13 & E-W & 219 & 0.342 & 8518 & 0.374 & 1059 & 25.5 & 511 & - & - & - \\
\hline 14 & $\mathrm{E}-\mathrm{W}$ & 86.2 & 0.37 & 2400 & 0.478 & 319 & - & - & - & - & - \\
\hline 15 & $\mathrm{E}-\mathrm{W}$ & 207.2 & 0.6 & 364.7 & 0.7719 & 693.1 & 1.765 & 744.3 & - & - & - \\
\hline 16 & $E-W$ & 50.4 & 0.385 & 1001 & 0.916 & 76.2 & 53.1 & 3779 & - & - & - \\
\hline 17 & E-W & 151 & 1.89 & 1957 & 1.67 & 392 & 74.5 & 447 & - & - & - \\
\hline 18 & E-W & 98.2 & 2.6 & 258 & 6.92 & 674 & 14.5 & 720 & - & - & - \\
\hline 19 & E-W & 105 & 5.54 & 300 & 1.67 & 486 & - & - & - & - & - \\
\hline 20 & E-W & 97.9 & 2.62 & 133 & 8.88 & 432 & 80.6 & 527 & - & - & - \\
\hline 21 & $E-W$ & 163 & 0.45 & 89.1 & 4.99 & 316 & 8.42 & 373 & - & - & - \\
\hline 22 & $E-W$ & 148 & 2.36 & 165 & 1.07 & 444 & 21.2 & 1290 & - & - & - \\
\hline 23 & $\mathrm{~N}-\mathrm{S}$ & 90 & 2.47 & 208 & 5.67 & 462 & 77.4 & 576 & - & - & - \\
\hline 24 & $\mathrm{~N}-\mathrm{S}$ & 28.4 & 0.343 & 197 & 0.454 & 38.5 & 4.14 & 80.8 & - & - & - \\
\hline 25 & N-S & 362 & 0.684 & 88.5 & 3.96 & 773 & - & - & - & - & - \\
\hline 26 & N-S & 208 & 3.79 & 82.2 & 10.6 & 37.1 & 14.8 & 54.9 & - & - & - \\
\hline 27 & $\mathrm{~N}-\mathrm{S}$ & 357 & 0.241 & 179 & 1.63 & 33.5 & 8.55 & 54 & - & - & - \\
\hline 28 & N-S & 293 & 4.87 & 79.4 & 17 & 189 & - & - & - & - & - \\
\hline 29 & $\mathrm{~N}-\mathrm{S}$ & 266 & 0.789 & 204 & 5.53 & 44.7 & - & - & - & - & - \\
\hline 30 & $E-W$ & 124 & 0.505 & 367 & 0.651 & 123 & 8.05 & 24.7 & 21.9 & 4751 & - \\
\hline 31 & E-W & 221 & 0.364 & 153 & 6.66 & 1303 & 64.7 & 1676 & - & - & - \\
\hline 32 & $\mathrm{~N}-\mathrm{S}$ & 324 & 2.63 & 108 & 7.59 & 458 & 3.26 & 1063 & - & - & - \\
\hline
\end{tabular}

The Overburden depths map was produced by contouring all the depths of the first layer at each VES point at an interval of $0.5 \mathrm{~m}$. The map is shown in figure5. The map shows the variation of the Overburden thickness from one place to another within the survey area. The thickness varies from 
0.2 to $5.2 \mathrm{~m}$, with an average of $2.1 \mathrm{~m}$. The lowest thickness is at VES27 where the depth to basement is as low as $10 \mathrm{~m}$. The surface plot in Figure6 shows a clearer variation in the Overburden thicknesses within the Area.

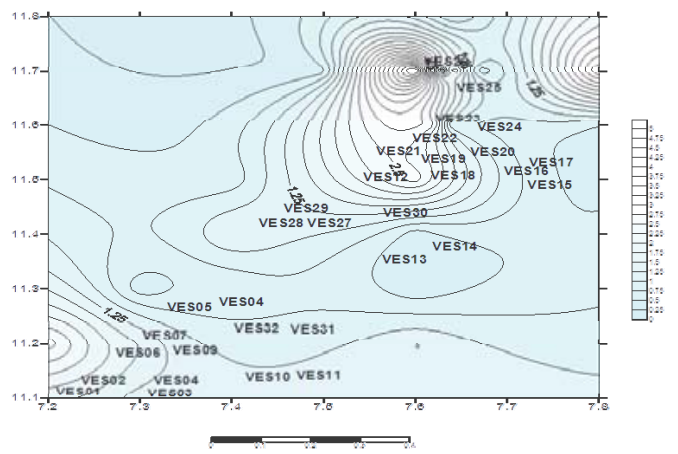

Figure5. Shows the contour map of the Overburden depths within the survey area.

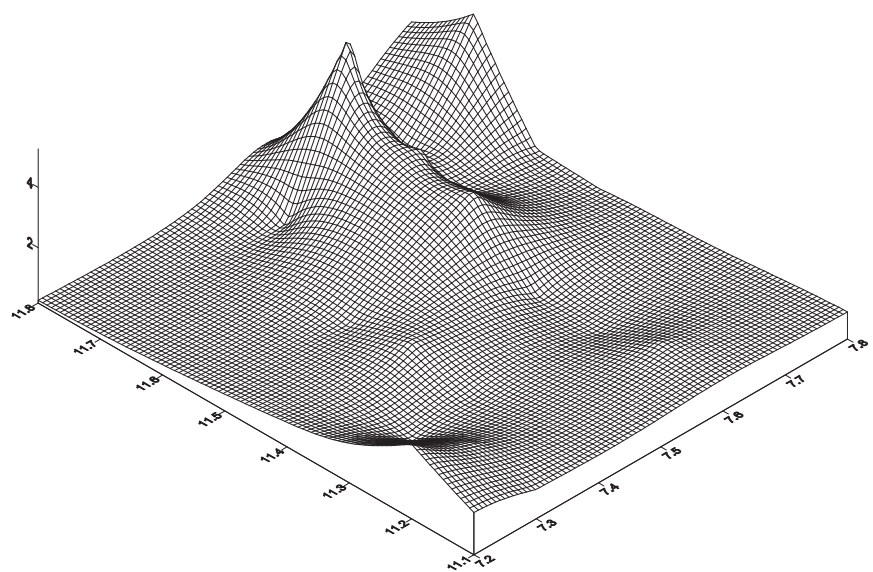

Figure 6. Shows the Surface plot of the Overburden depths.

\section{Conclusion}

The survey area is dominated by mainly four layers, namely: Overburden, Weathered basement, fractured basement and Fresh basement. The overburden consists of laterites, clay and fadama loam. The results of the interpreted VES data showed that The Overburden depth varies from 1.2 to $7.2 \mathrm{~m}$, with an average of $4.1 \mathrm{~m}$. The lowest overburden thickness is at VES20 where the depth to basement is as low as $10 \mathrm{~m}$. A map was produced by contouring all the depths of the overburden layers at each VES point at an interval of $0.5 \mathrm{~m}$. The map shows the variation of the Overburden depth from one place to another within the survey Area, which is an indication of the inhomogenuity of the subsurface structures. VES Points where the thickness of the Overburden is large also have large Aquifer thickness and vice-versa. There is also correlation between the Overburden thickness and depth to basement; Areas where the Overburden thickness is low have low depth to basement, such areas are considered suitable for waste disposal system, owing to the fact that the groundwater potential in such areas are not sustainable. 


\section{References}

Aboh, H.O. (2001). Detailed Regional Geophysical Investigation of the Subsurface Structures in Kaduna Area, Nigeria. Unpublished PhD Thesis, A.B.U, Zaria.

Afuwai, G.C, Lawal, K.M, and Aminu, A.L (2011). Investigation of Groundwater Potential at Samaru College of Agriculture, Ahmadu Bello University, Zaria-Nigeria. Unpublished M.Sc Thesis. Ahmadu Bello University, Zaria-Nigeria.

Hore, P.N. (1970). Weather and Climate: Zaria and its region. Ed. By M.J. Mortimore, Dept of Geography, Occasional Paper no. 4, A.B.U, Zaria, pp 41-54.

Shemang, E.M. (1990). Electrical Depth Sounding at Selected Well sites within Kubani River Basin, Zaria. Unpublished M.Sc Thesis, A.B.U, Zaria. 